\title{
Involvement of the L-Type Amino Acid Transporter Lat2 in the Transport of 3,3'-Diiodothyronine across the Plasma Membrane
}

\author{
Anita Kinne $^{\mathrm{a}}$ Melanie Wittner ${ }^{\mathrm{a}}$ Eva K. Wirth ${ }^{\mathrm{b}}$ Katrin M. Hinz ${ }^{\mathrm{a}}$ Ralf Schülein ${ }^{\mathrm{a}}$ \\ Josef Köhrle $^{b}$ Gerd Krause ${ }^{a}$ \\ a Leibniz-Institut für Molekulare Pharmakologie (FMP), and ${ }^{\mathrm{b}}$ Institut für Experimentelle Endokrinologie, \\ Charité-Universitätsmedizin Berlin, Berlin, Germany
}

\section{Key Words}

Thyroid hormones · Transporters · L-type amino acid transporter $2 \cdot$ Molecular uptake $\cdot 3,3^{\prime}$-Diiodothyronine $\cdot T_{3}$. Oocytes

\begin{abstract}
Thyroid hormones are transported across cell membranes by transmembrane transporter proteins, for example by members of the monocarboxylate transporter (MCT) and the L-type amino acid transporter (LAT) families. LATs consist of a light chain (e.g. LAT2) and a heavy chain (CD98), which is essential for their cell surface expression and functionality. The specificity of Lat2 for thyroid hormones and their metabolites and its role in their transport was not fully clear. This fact motivated us to establish a cell system to elucidate the uptake of thyroid hormones and their metabolites by mouse Lat2. The coinjection of CRNA coding for Lat2 and CD98 into Xenopus laevis oocytes resulted in a markedly increased level of $3,3^{\prime}$-diiodo-L-thyronine $\left(3,3^{\prime}-T_{2}\right)$ and to some extent also enhanced $\mathrm{T}_{3}$ transport. To gain insight into properties of thyroid hormones and their metabolites transported by Lat2, we inhibited $3,3^{\prime}-T_{2}$ uptake by various iodothyronine derivatives. $T_{1}$ and $T_{2}$ derivatives as well as 2 -aminobicyclo-[2,2,1]heptane-2-carboxylic acid strongly competed with $3,3^{\prime}-T_{2}$ uptake. In addition, we performed $\mathrm{T}_{2}$ uptake measurements
\end{abstract}

with the thyroid hormone-specific transporter MCT8. For both Lat2 and MCT8, $\mathrm{K}_{\mathrm{m}}$ values in a low micromolar range were calculated. We demonstrated that oocytes are a suitable system for thyroid hormone transport studies mediated by Lat2. Our data indicates that Lat 2 compared to other thyroid hormone transporters prefers $3,3^{\prime}-\mathrm{T}_{2}$ as the substrate. Thus, Lat2 might contribute to the availability of thyroid hormone by importing and/or exporting $3,3^{\prime}-T_{2}$, which is generated either by $T_{3}$ inactivation or by rapid deiodinase 1 -mediated $\mathrm{rT}_{3}$ degradation.

(c) 2015 European Thyroid Association Published by S. Karger AG, Basel

\section{Introduction}

Thyroid hormones are essential for processes such as the development of the human brain, growth and metabolism [1-3]. For their intracellular availability thyroid hormones are transported across cell membranes by a variety of thyroid hormone transmembrane transporter proteins. Several transporters with high affinity for thyroid hormones but with different tissue distributions and ligand affinities have been identified. They include members of the monocarboxylate transporter (MCT), organic anion-transporting polypeptide (OATP) and L-type amino acid transporter (LAT) families $[4,5]$. 
LAT2 expression studies in the human and mouse brain showed no expression of LAT2 in developing neurons of the human, while expression is clearly present in mouse neurons at all stages of development [6]. In murine neurons and astrocytes Lat2 is coexpressed with Mct8 and Lat1. To study the role of Lat2 in the transport of thyroid hormones, Lat 2 knock-out mice were analyzed by Braun et al. [7]. The animals display a significantly reduced $\mathrm{T}_{3}$ uptake in primary astrocytes, which confirms the participation of Lat2 in the transport of thyroid hormones in brain cells. Together with others we have suggested that coexpression of Lat 2 in neurons complements the inactivation of $M c t 8$ in mice $[6,7]$.

The characterization of Lat2-deficient mice showed normal growth and development. Movement coordination is slightly impaired indicating light neurobehavioral alterations, although cerebellar development and structure remained inconspicuous $[1,8]$. Circulating thyroid hormones, thyroid-stimulating hormone and thyroid hormone-responsive genes remained unchanged, possibly because of functional compensation by Mct8 [8]. The role of Lat2 during the early postnatal cerebral cortex development is indicated by the combined Mct8/Lat2 mouse [9].

Lat2 was first identified as a sodium-independent transporter protein of large and neutral amino acids, such as alanine, phenylalanine and leucine, and requires association with CD98 (4F2 heavy chain, $4 \mathrm{f} 2 \mathrm{hc}$ ) for its cell surface expression. The so-called light chain, Lat2, consists of 12 transmembrane helices (TMHs), whereas the heavy chain, CD98, shows only 1 transmembrane helix with a large extracellular C-terminal domain. Both chains are proposed to be linked via a disulphide bridge [10-12]. Lat2 is not only expressed in the brain, but also in the kidney, intestine and liver $[7,8]$. As already mentioned, studies indicate the involvement of Lat 2 in the transport of thyroid hormones $[7,13]$, but its role in the transport of these hormones, such as $\mathrm{T}_{3}$ or the metabolite $3,3^{\prime}-\mathrm{T}_{2}$, including its thyroid hormone substrate specificity, is still unclear. So far, transport studies by LAT2 have mainly been performed in oocytes from Xenopus laevis $[10,11,13]$. Using this cell system and the known LAT inhibitor 2-aminobicyclo-(2,2,1)-heptane-2-carboxylic acid $(\mathrm{BCH})$ we observed a preferential uptake of $3,3^{\prime}-\mathrm{T}_{2}$ by Lat 2 and its strong competition by thyroid hormone metabolites, such as $3-\mathrm{T}_{1}$ and other $\mathrm{T}_{2}$ isomers. In comparison to the uptake of $3,3^{\prime}-\mathrm{T}_{2}$, only limited $\mathrm{T}_{3}$ uptake was detectable. Our results indicate that Lat2 is involved in the transport of thyroid hormones across cell membranes and participates in the regulation of intracellular availability or cellular release of these hormones.

\section{Materials and Methods}

\section{Materials}

Iodo-L-thyronines $\left(3,3^{\prime}-\mathrm{T}_{2}, \mathrm{~T}_{3}, \mathrm{rT}_{3}, \mathrm{~T}_{4}\right), \mathrm{L}$-amino acids (Leu, IIe, Met, His) and $\mathrm{BCH}$ were obtained from Sigma (St. Louis, Mo., USA). All iodothyronines were dissolved in DMSO. $\left[{ }^{125} \mathrm{I}\right] \mathrm{rT}_{3},\left[{ }^{125} \mathrm{I}\right] \mathrm{T}_{4}$ and $\left[{ }^{14} \mathrm{C}\right]$ Leu were purchased from Perkin Elmer (Boston, Mass., USA). [ $\left.{ }^{125} \mathrm{I}\right] 3,3^{\prime}-\mathrm{T}_{2}$ and $\left[{ }^{125} \mathrm{I}\right] \mathrm{T}_{3}$ were purchased from Hartmann Analytic GmbH (Braunschweig, Germany). All other chemicals were of reagent grade.

\section{Plasmids}

Murine Lat2 and CD98 were amplified from kidney cDNA and cloned into the expression vector pcDNA3 (Invitrogen, Carlsbad, Calif., USA) [6]. The C-terminal FLAG-tag was introduced into Lat2-pcDNA3 by oligonucleotide-based cloning using PpuMI and XbaI. An additional BamHI restriction site for CD98-pcDNA3 was carried out by site-directed mutagenesis with the QuikChange Kit (Stratagene, Heidelberg, Germany). The C-terminal His tag was introduced into CD98-pcDNA3 by oligonucleotide-based cloning using BamHI and XbaI.

Both constructs were cloned into the pTLB expression vector [14], which was kindly provided by T.J. Jentsch (Leibniz-Institut für Molekulare Pharmakologie, Berlin, Germany). For stable transfection of MDCK1 cells CD98-His was cloned into pcDNA3.1Hygro $^{(+)}$(Invitrogen) using HindIII and XbaI. Clones of human MCT8 in pcDNA3 and empty pcDNA3 were used for stable transfection of MDCK1 cells as previously described [15].

\section{Transfection of MDCK1 Cells}

Cells at 50\% confluency were transfected with Lat2-FLAGpcDNA3 or CD98-His-pcDNA3.1Hygro ${ }^{(+)}$and exposed to selective pressure with $400 \mu \mathrm{g} / \mathrm{ml}$ of G418 or $50 \mu \mathrm{g} / \mathrm{ml}$ of hygromycin for 2 weeks, respectively. Derived clones were used for stable cotransfection. The expression was ascertained by SDS-PAGE and immunoblotting with FLAG or CD98 antibody.

cRNA Preparation and Injection into Isolated X. laevis Oocytes

Plasmids containing CD98-His or Lat2-FLAG in PTLB were cut by MluI. Linearized plasmids were transcribed using the mMESSAGE mMACHINE ${ }^{\circledR}$ SP6 RNA Transcription Kit (Life Technologies GmbH, Darmstadt, Germany) following the manufacturer's protocol.

Oocytes were kindly provided and isolated by the group of T.J. Jentsch or prepared by EcoCyte Bioscience (Castrop-Rauxel, Germany). Stage V-VI oocytes (35) were sorted on morphological criteria and kept at $18^{\circ} \mathrm{C}$ in ND96 containing $96 \mathrm{mM} \mathrm{NaCl}$, $2 \mathrm{mM} \mathrm{KCl}, 1.8 \mathrm{mM} \mathrm{CaCl}_{2}, 1 \mathrm{mM} \mathrm{MgCl}, 5 \mathrm{mM}$ HEPES and 50 $\mathrm{mg} / \mathrm{ml}$ gentamycin ( $\mathrm{pH} 7.5$ ). Oocytes were injected with $23 \mathrm{ng}$ CD98-His and/or $23 \mathrm{ng}$ Lat2-FLAG cRNA or $46 \mathrm{nl}$ of RNase-free water.

\section{Uptake Assays}

After 2 days of expression oocytes were washed with washing buffer $\left(100 \mathrm{mM} \mathrm{NaCl}\right.$ or $100 \mathrm{mM} \mathrm{ChCl,} 2 \mathrm{mM} \mathrm{KCl}, 1 \mathrm{mM} \mathrm{CaCl}_{2}$, $1 \mathrm{mM} \mathrm{MgCl}_{2}, 10 \mathrm{mM}$ HEPES, $10 \mathrm{mM}$ Tris, $0.1 \%$ BSA, pH 7.5). For the thyroid hormone uptake assay oocytes were incubated in 600 $\mu \mathrm{l}$ of uptake buffer (washing buffer containing $100 \mathrm{nM}$ L-iodothyronine and $0.1 \mathrm{nM}$ of the corresponding ${ }^{125} \mathrm{I}$-labeled iodothyronine). Further oocytes were washed six times with ice-cold wash- 
ing buffer. Radioactivity was determined by a gamma counter (Wizard; PerkinElmer, Waltham, Mass., USA).

Two days before the experiments with stably transfected MDCK1 cells (MCT8, pcDNA3), 100,000 cells per well were seeded into 24-well plates. For time course assays, cells were washed once with PBS and incubated with uptake buffer $(125 \mathrm{mM}$ $\mathrm{NaCl}, 5 \mathrm{mM} \mathrm{KCl}, 1.3 \mathrm{mM} \mathrm{CaCl}_{2}, 1.2 \mathrm{mM} \mathrm{MgCl}_{2}, 25 \mathrm{mM}$ HEPES, $0.1 \%$ BSA, $5.6 \mathrm{~mm}$ glucose, $\mathrm{pH}$ 7.4) supplemented with $10 \mathrm{nM}$ $3,3^{\prime}-\mathrm{T}_{2}$.

For competitive inhibition studies, cells were exposed to 100

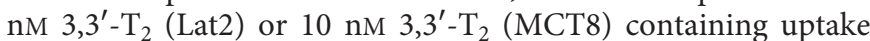
buffer with $0.1 \mathrm{nM}$ of the corresponding radioactive ${ }^{125}$ I-labeled thyroid hormone. Incubation for 60 or $2 \mathrm{~min}$, respectively, was performed in the presence or absence of test compounds $(10 \mu \mathrm{M}$ iodothyronines, $1 \mathrm{mM}$ or $100 \mu \mathrm{M} \mathrm{BCH}, 1 \mathrm{mM}$ amino acid).

For L-Leu uptake, oocytes and MDCK1 cells were incubated with uptake buffer without BSA for $10 \mathrm{~min}$, and washed with icecold buffer or PBS, respectively. The radioactivity of cells was measured using a beta counter (Wallac, Perkin Elmer). L-Leu was dissolved in uptake buffer with the following concentrations: 500 $\mathrm{nm}\left[{ }^{14} \mathrm{C}\right] \mathrm{L}$-Leu plus $10 \mu \mathrm{M}$ nonlabeled L-Leu for MCT8 or $50 \mu \mathrm{M}$ L-Leu for Lat2/CD98 transport studies, respectively. Each experiment was performed at least twice with two different batches of oocytes and cRNAs or in triplicates for MDCK1 cells, respectively.

\section{Transport Kinetics}

Saturation of $3,3^{\prime}-\mathrm{T}_{2}$ uptake in Lat2/CD98 coinjected oocytes was analyzed after $60 \mathrm{~min}$ of incubation in uptake buffer without BSA containing $3,3^{\prime}-\mathrm{T}_{2}$ at final concentrations of $0.1-25 \mu \mathrm{M}$ containing $\left[{ }^{125} \mathrm{I}\right] 3,3^{\prime}-\mathrm{T}_{2}$ as tracer. Transport kinetics of $3,3^{\prime}-\mathrm{T}_{2}$ uptake by MCT8-transfected MDCK1 cells were measured for $2 \mathrm{~min}$ in uptake buffer without BSA. $3,3^{\prime}-\mathrm{T}_{2}$ concentrations ranged from 0.5 to $12 \mu \mathrm{M}$ containing $\left[{ }^{125} \mathrm{I}\right] 3,3^{\prime}-\mathrm{T}_{2}$ as tracer.

\section{Western Blot}

Stably transfected MDCK1 cells or oocytes (2 days after Lat2/ CD98 injection) were lysed in homogenization buffer $(250 \mathrm{mM}$ saccharose, 20 mM HEPES, 1 mM EDTA, pH 7.4) and treated with ultrasound. For oocytes the buffer was supplemented with $1 \mathrm{mM}$ DTT.

Equal amounts of cell lysates were separated on SDS gels, transferred onto nitrocellulose membranes and probed with antibodies for Lat2 (a kind gift from Ulrich Schweizer, Rheinische FriedrichWilhelms-Universität Bonn, and Eva K. Wirth, Charité-Universitätsmedizin Berlin), FLAG (Cell Signaling Technology; Danvers, Mass., USA) or CD98 (Santa Cruz Biotechnology, Dallas, Tex., USA). The experiments were performed at least twice.

\section{Statistics}

Data are presented as means \pm SD or means \pm SEM after the subtraction of noninjected or empty-vector transfected cells, respectively. The kinetic parameters were determined by fitting the plot of uptake rate (v) versus ligand concentration (S) to the Michaelis-Menten equation: $\mathrm{v}=\mathrm{V}_{\max } /\left(1+\mathrm{K}_{\mathrm{m}} / \mathrm{S}\right)$, where $\mathrm{V}_{\max }$ is the maximum uptake rate and $\mathrm{K}_{\mathrm{m}}$ is the Michaelis constant. Calculations were performed using GraphPad Prism 4.0.

\section{Results}

\section{Substrate Specificity}

Initial experiments were carried out to reproduce the previously described induction of amino acid transport in cRNA microinjected $X$. laevis oocytes $[10,11]$ and stably transfected MDCK1 cells. The expression of Lat2 and CD98 in both cell systems was confirmed by Western blotting using antibodies against Lat2, FLAG or CD98 (online suppl. fig. S2A-D; for all online suppl. material, see www.karger.com/doi/10.1159/000381542).

Uninjected oocytes showed negligible uptake of the neutral amino acid L-Leu. Online supplementary figure S1 shows uptake of L-Leu in Lat2/CD98 coinjected oocytes or in Lat2/CD98 stably transfected MDCK1 cells. Coexpression of Lat2/CD98 resulted in a large induction (about 16-fold) in L-Leu uptake in oocytes, while a lower increase in L-Leu uptake was determined in Lat2/CD98expressing MDCK1 cells (online suppl. fig. S1). Based on these functional results we used the oocyte system for further Lat2 transport studies.

Figure 1a shows the uptake of $100 \mathrm{~nm}$ iodothyronines $\left(\mathrm{T}_{4}, \mathrm{rT}_{3}, \mathrm{~T}_{3}, 3,3^{\prime}-\mathrm{T}_{2}\right)$ by noninjected oocytes and oocytes injected with cRNAs coding for Lat2 and CD98 after 60 min of incubation in $\mathrm{Na}^{+}$-free uptake buffer. The coexpression of both chains induces the uptake of $3,3^{\prime}-\mathrm{T}_{2}$ by a factor of 4 and only to a lower extent the uptake of $\mathrm{T}_{3}$. The lower induction of $\mathrm{T}_{3}$ uptake seems to be the result of a higher background uptake. Thyroid hormones $\mathrm{T}_{4}$ and $\mathrm{rT}_{3}$ were not transported into oocytes by Lat2. The specific $3,3^{\prime}-\mathrm{T}_{2}$ uptake over time was calculated after the subtraction of uptake in noninjected oocytes as background (fig. 1b, c).

Functional properties of $3,3^{\prime}-\mathrm{T}_{2}$ transport by Lat 2 were examined by the single expression of Lat 2 or CD98 and coexpression of Lat2/CD98 in X. laevis oocytes (fig. 2a). As shown in figure $2 a$, the expression of Lat 2 alone is not sufficient for $3,3^{\prime}-\mathrm{T}_{2}$ transport. The coexpression of Lat 2 and CD98 resulted in a large $3,3^{\prime}-\mathrm{T}_{2}$ uptake, indicating that CD98 is indispensable for the functional expression of Lat2.

To clarify a sodium dependence of $3,3^{\prime}-\mathrm{T}_{2}$ uptake by Lat2, uptake assays were performed in $\mathrm{Na}^{+}$- or $\mathrm{Ch}^{+}$-containing uptake buffer. After subtraction of the background, we could characterize $3,3^{\prime}-\mathrm{T}_{2}$ uptake as sodium independent (fig. 2b, c).

\section{Transport Kinetics}

Saturation kinetics of $3,3^{\prime}-\mathrm{T}_{2}$ uptake by Lat 2 were studied by incubation of noninjected oocytes and oocytes 


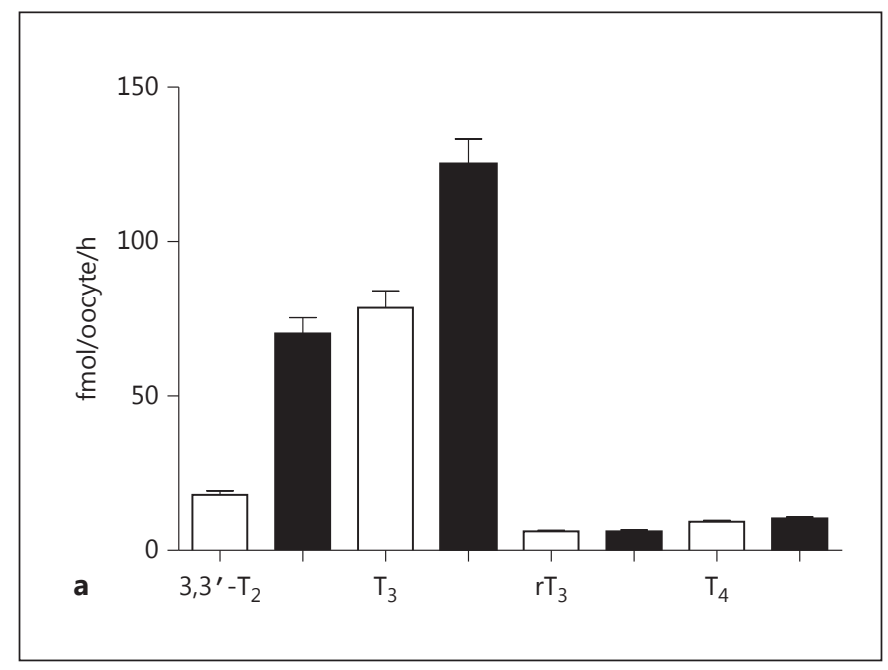

Fig. 1. Lat2-mediated thyroid hormone transport in X. laevis oocytes. a Uptake of $100 \mathrm{nM} \mathrm{T}, \mathrm{T}_{3}, \mathrm{rT}_{3}$ and $3,3^{\prime}-\mathrm{T}_{2}$ was measured after $60 \mathrm{~min}$ in $\mathrm{Na}^{+}$-free uptake buffer in oocytes coexpressing Lat2 and CD98 (black columns) or noninjected oocytes (white columns). The highest uptake rates were determined with $3,3^{\prime}-\mathrm{T}_{2}$ and $\mathrm{T}_{3}$. Data represent one of at least three independent experiments performed with 9-12 oocytes. b, c 3, $3^{\prime}-\mathrm{T}_{2}$ uptake by Lat 2 is time dependent. $\mathbf{b}$ The time course of $3,3^{\prime}-\mathrm{T}_{2}$ uptake into oocytes coexpressing Lat2 and CD98 $(\bullet)$ or noninjected ( $)$ oocytes in $\mathrm{Na}^{+}-$ free uptake buffer. Uptake was measured after incubation with 100 nM 3,3'- $\mathrm{T}_{2}$ for $1-120 \mathrm{~min}$. c Specific $3,3^{\prime}-\mathrm{T}_{2}$ uptake by Lat2. Uptake by noninjected oocytes was considered as background and subtracted in subsequent experiments $(\Delta)$. All data points were determined in 10-13 oocytes.

injected with Lat2 and CD98 cRNAs for 60 min with $0.1-$ $25 \mu \mathrm{M}$ concentrations of the substrate in $\mathrm{Ch}^{+}$-containing buffer. The results are presented in figure $3 \mathrm{a}$ and b. $3,3^{\prime}-\mathrm{T}_{2}$ transport by Lat2/CD98 was determined by subtraction of the uptake rates in noninjected oocytes from those observed in oocytes injected with the cRNAs for both subunits.

\section{Competition Studies on Thyroid Hormone Uptake}

Competitive transport experiments by Lat 2 were stud-

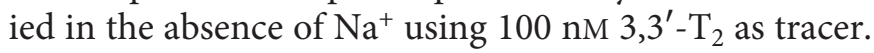
Oocytes were coinjected with CD98 and Lat 2 and corrected for uptake in noninjected oocytes. Uptake without an inhibitor was set to $100 \%$.

The specificity of iodothyronine uptake by Lat2/CD98 was investigated using the known Lat inhibitor $\mathrm{BCH}$,
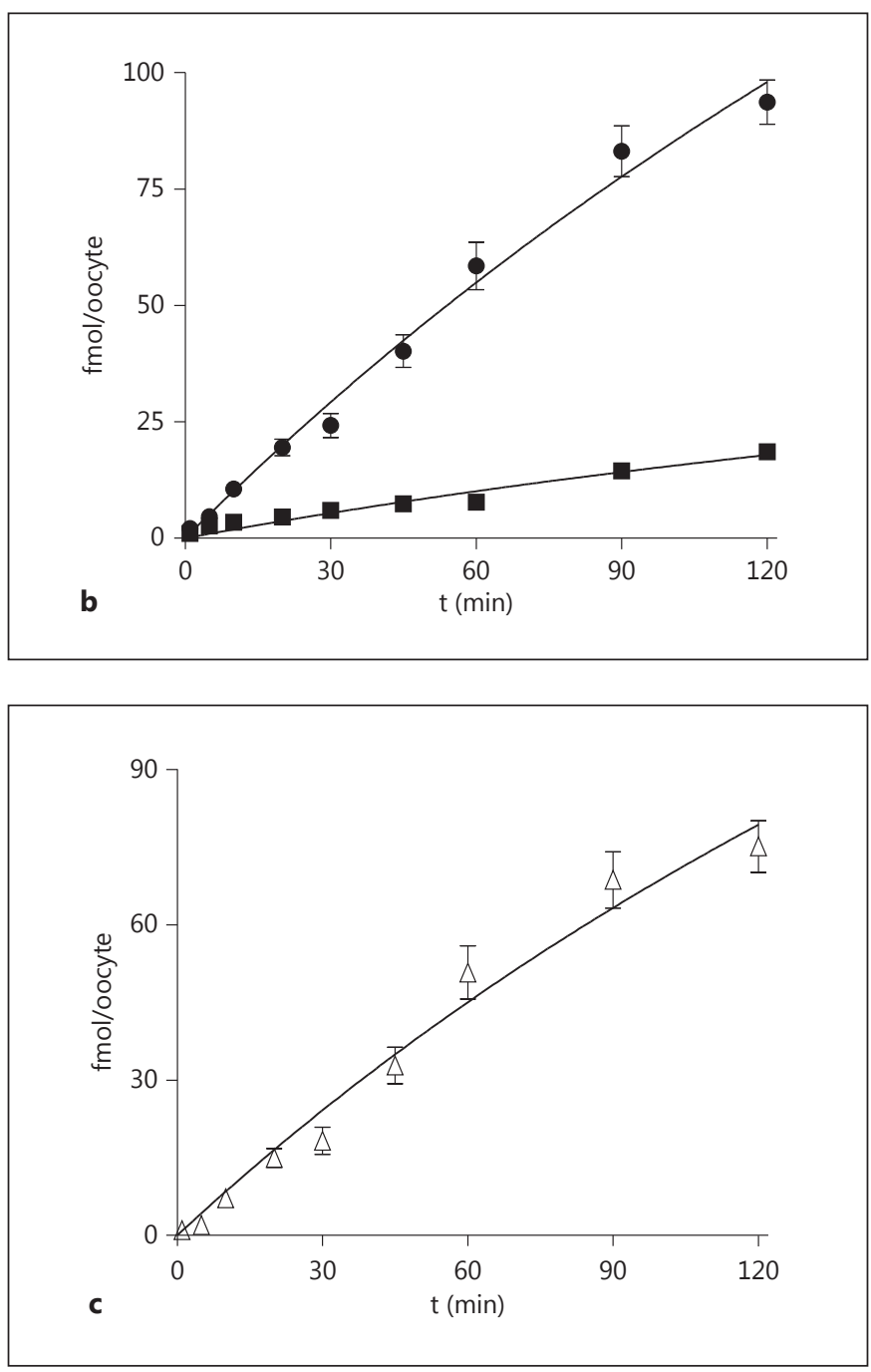

amino acids and several iodothyronines as agents potentially interfering with $3,3^{\prime}-\mathrm{T}_{2}$ uptake (fig. 4). A potent inhibition of about $80 \%$ on $3,3^{\prime}-\mathrm{T}_{2}$ uptake was determined for $\mathrm{BCH}$ at a concentration of $1 \mathrm{mM}$. Tested at $100 \mu \mathrm{M}$, $\mathrm{BCH}$ produced at least the same marked inhibition of $3,3^{\prime}-\mathrm{T}_{2}$ uptake as $3,3^{\prime}-\mathrm{T}_{2}$ itself (fig. $4 \mathrm{a}$ ).

Competition between iodothyronine and amino acid transport by Lat 2 was studied by testing the effects of $1 \mathrm{~mm}$ of unlabeled amino acid on the uptake of $3,3^{\prime}-\mathrm{T}_{2}$. Figure $4 \mathrm{~b}$ illustrates the inhibition by L-Leu, L-Ile, L-Met and L-His. Uptake of 3,3'- $\mathrm{T}_{2}$ was reduced between 80 and 95\% depending on the amino acid tested, whereas the strongest inhibition was measured with L-Ile and L-Leu. In addition, the effect of several iodothyronines $(10 \mu \mathrm{M})$ was investigated on 3,3'- $\mathrm{T}_{2}$ uptake. As shown in figure 4c, $3,3^{\prime}-\mathrm{T}_{2}$ uptake by Lat 2 was inhibited by iodothyronines 


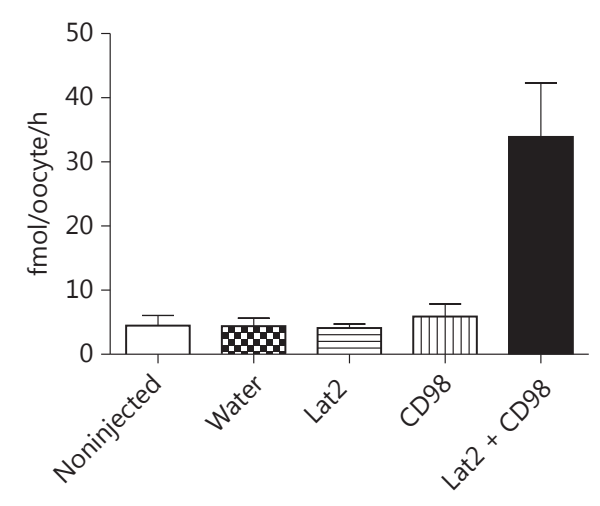

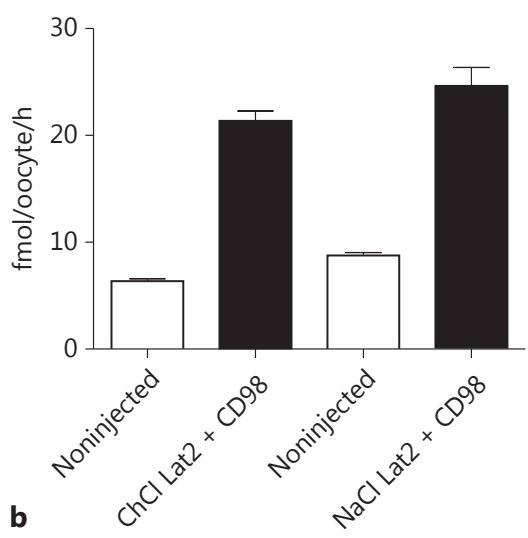

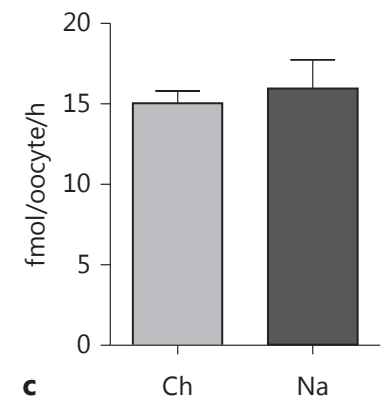

Fig. 2. Functional expression of Lat 2 in X. laevis oocytes. a Effect of coexpression of Lat 2 and CD98 on $3,3^{\prime}-\mathrm{T}_{2}$ uptake. The uptake of $100 \mathrm{nM} 3,3^{\prime}-\mathrm{T}_{2}$ was measured after $60 \mathrm{~min}$ in $\mathrm{Na}^{+}$-free uptake solution on noninjected oocytes or oocytes injected with water, Lat 2 or CD98 cRNA, or both, 2 days after injection. The coexpression of Lat2 and CD98 resulted in a marked uptake of $3,3^{\prime}-\mathrm{T}_{2} \cdot \mathbf{b}$, c Ion dependence of $3,3^{\prime}-\mathrm{T}_{2}$ transport in oocytes that express Lat2 and CD98. b Noninjected or Lat 2 and CD98 coexpressing oocytes were incubated for 60 min with $100 \mathrm{nM} 3,3^{\prime}-\mathrm{T}_{2}$ in $\mathrm{NaCl}$ or $\mathrm{ChCl}$ containing buffer. c $3,3^{\prime}-\mathrm{T}_{2}$ uptake by noninjected oocytes was considered as background and subtracted. Uptake of 3,3'- $\mathrm{T}_{2}$ measured in $\mathrm{Na}^{+}$uptake solution (Na) was not different from uptake medium containing choline ${ }^{+}(\mathrm{Ch})$. Data represent one of at least two independent uptake experiments performed with 10-14 oocytes.

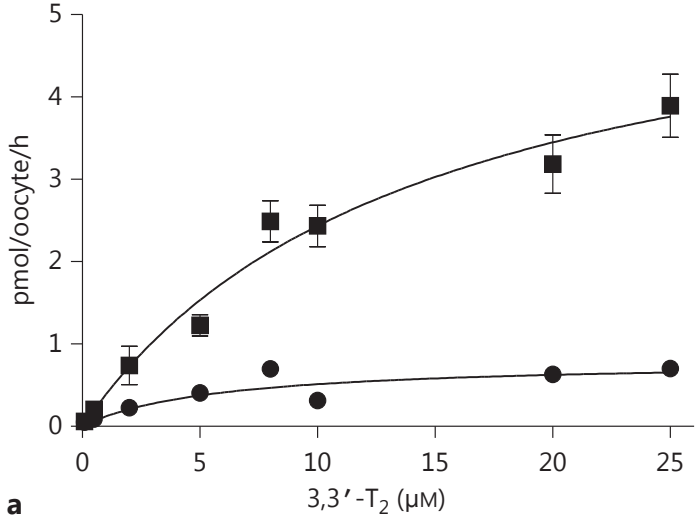

Fig. 3. Concentration dependence of Lat2-mediated $3,3^{\prime}-\mathrm{T}_{2}$ uptake. a Two days after injection, $3,3^{\prime}-\mathrm{T}_{2}$ uptake was measured at different substrate concentrations $(0.1-25 \mu \mathrm{M})$ in $\mathrm{Na}^{+}$-free uptake buffer in noninjected $(\bullet)$ or Lat 2 and CD98 coexpressing ( $\boldsymbol{\square}$ ) oocytes after $60 \mathrm{~min}$. b The transport activity of noninjected oocytes

without iodine substituents or containing up to three iodine atoms. In contrast, $3,3^{\prime}-\mathrm{T}_{2}$ uptake by MCT 8 was only strongly inhibited by iodothyronines carrying at least one iodine atom per aromatic ring [15] (fig. 5e).

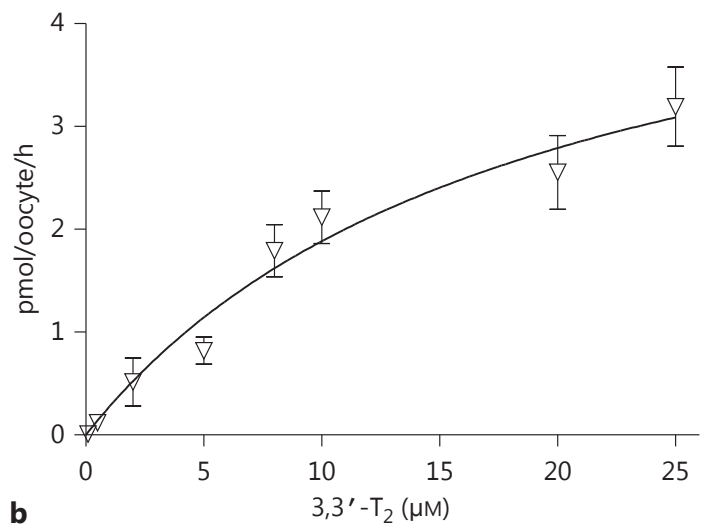

was subtracted from that of cRNA-injected oocytes $(\nabla)$. A Michaelis-Menten transport mechanism was assumed for calculations (GraphPad 4.0). Data correspond to a representative experiment with 8-10 oocytes per group. The kinetic parameters were $\mathrm{V}_{\max }=5.4 \mathrm{pmol} / 60 \mathrm{~min}$ and $\mathrm{K}_{\mathrm{m}}=18.6 \mu \mathrm{M}$.

\section{MCT8 Studies}

$3,3^{\prime}-\mathrm{T}_{2}$ transport studies by MCT8 were performed in MDCK1 cells as previously described [15]. Figure 5 shows the time course of $3,3^{\prime}-\mathrm{T}_{2}$ uptake in pcDNA3 and MCT8 stably transfected cells. Expression of MCT8 induced a 6 -fold increase in the initial uptake of 3,3'- $\mathrm{T}_{2}$ compared 
with the control, and the 3,3'- $\mathrm{T}_{2}$ transport into MCT8expressing cells was only linear for the first $4 \mathrm{~min}$. Therefore, all further transport experiments were performed at 2-min incubations.

To determine the $\mathrm{K}_{\mathrm{m}}$ value of $3,3^{\prime}-\mathrm{T}_{2}$ for MCT8, stably transfected MDCK1 cells were incubated with substrate concentrations ranging from 0.5 to $12 \mu \mathrm{M}$ for $2 \mathrm{~min}$. After the subtraction of pcDNA3-transfected MDCK1 as background from MCT8-expressing cells, Michaelis-Menten analysis provided apparent $\mathrm{K}_{\mathrm{m}}$ values of $18.6 \mu \mathrm{M}$ in oocytes and $2.6 \mu \mathrm{M}$ in MDCK1 cells for $3,3^{\prime}-\mathrm{T}_{2}$ for Lat 2 or MCT8, respectively.

\section{Discussion}

In this study, we used $X$. laevis oocytes to establish a cell system to investigate the transport of thyroid hormones and their metabolites by Lat 2 . Oocytes represent a well-described system that is widely used in transport studies. They have been used to characterize the thyroid hormone transporters MCT8 and LAT1 in vitro $[13,16]$. The endogenous expression of transport proteins in this system is low, leading to only minor levels of background transport activity [17].

To show the functionality of Lat 2 expression, we analyzed the transport of the known substrate L-Leu. For this purpose, we injected oocytes with cRNAs coding for Lat2 and CD98 and stably transfected MDCK1, which we used for thyroid hormone uptake studies by MCT8 [15].

Although both systems showed marked uptake of the substrate, the endogenous leucine uptake in oocytes was much lower than in MDCK1 cells. The presence of endogenous amino acid transporters other than Lat 2 in this cell line is plausible. MDCK1 cells are isolated from the kidney, where amino acids need to be reabsorbed.

The highest uptake rate by Lat 2 in oocytes was determined for 3,3'- $\mathrm{T}_{2}$ (about 4-fold). However, transport of $\mathrm{T}_{3}$ is only mildly induced by the coexpression of CD98 and Lat2 (about 1.6-fold). By testing different iodothyronine concentrations (10-100 nM) we could not enhance the uptake of $\mathrm{T}_{3}$, which remained low, while $\mathrm{rT}_{3}$ and $\mathrm{T}_{4}$ are not transported by Lat2. These results support and extend similar studies with human LAT1 and human LAT2 $[13,18,19]$.

Previously it was demonstrated by others that LAT1 and, albeit less effectively, also Lat2 is capable of transporting iodothyronines. In contrast to Lat2, LAT1 markedly induced the uptake of $\mathrm{rT}_{3}$ when coexpressed with
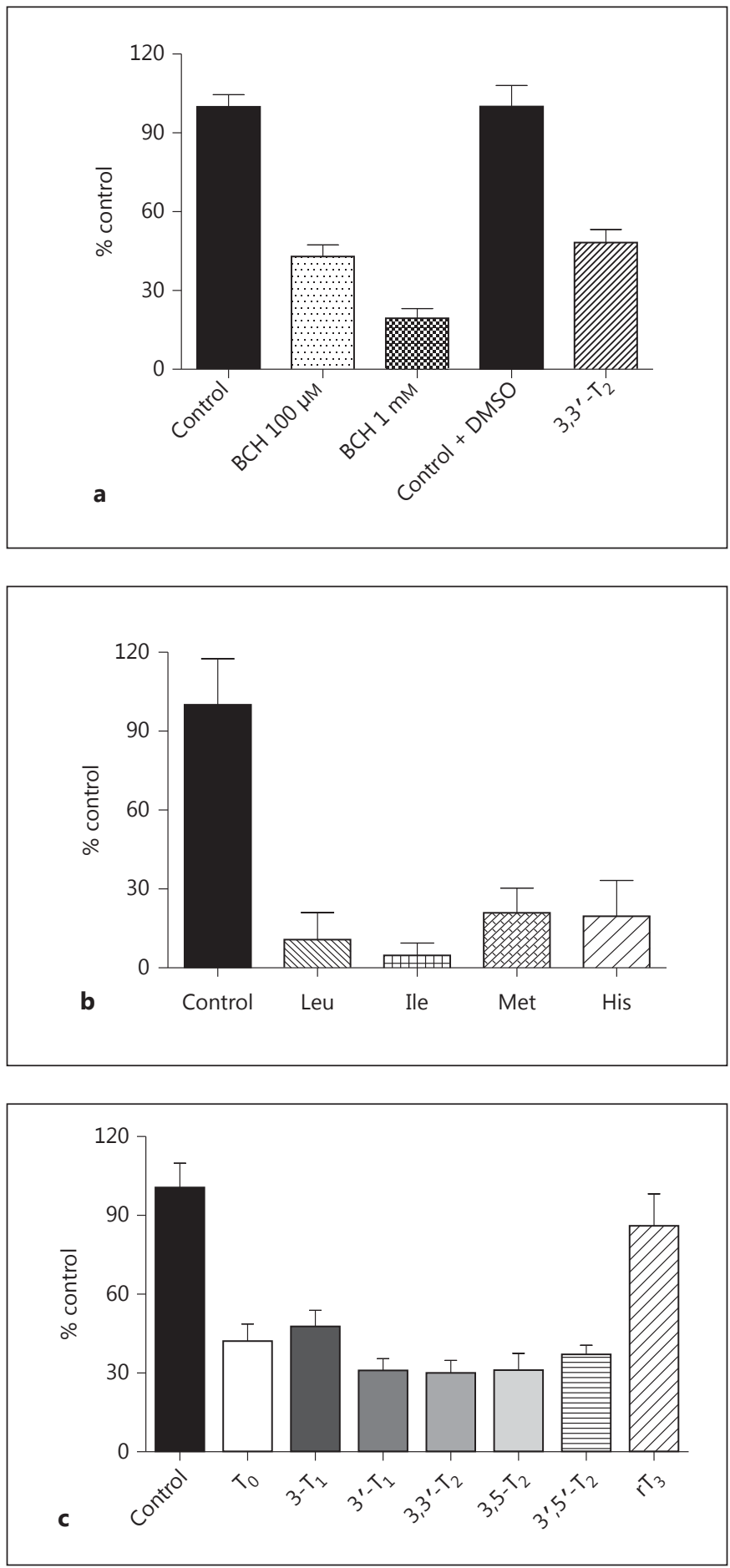

Fig. 4. Inhibition of $3,3^{\prime}-\mathrm{T}_{2}$ uptake by Lat2. X. laevis oocytes were coinjected with Lat 2 and CD98 cRNAs and the uptake of $3,3^{\prime}-\mathrm{T}_{2}$ was measured after an incubation time of $60 \mathrm{~min}$ in $\mathrm{Na}^{+}$-free uptake buffer. 3,3'- $\mathrm{T}_{2}$ uptake of noninjected oocytes was considered as background and subtracted. Uptake without inhibitor was set to $100 \%$. Inhibition on $3,3^{\prime}-\mathrm{T}_{2}$ uptake by $\mathrm{BCH}(100 \mu \mathrm{M}$ and $1 \mathrm{mM})$ and $3,3^{\prime}-\mathrm{T}_{2}(10 \mu \mathrm{M} ; \mathbf{a}), 1 \mathrm{mM}$ amino acids (b) and $10 \mu \mathrm{M}$ iodothyronine derivatives $(\mathbf{c})$. 


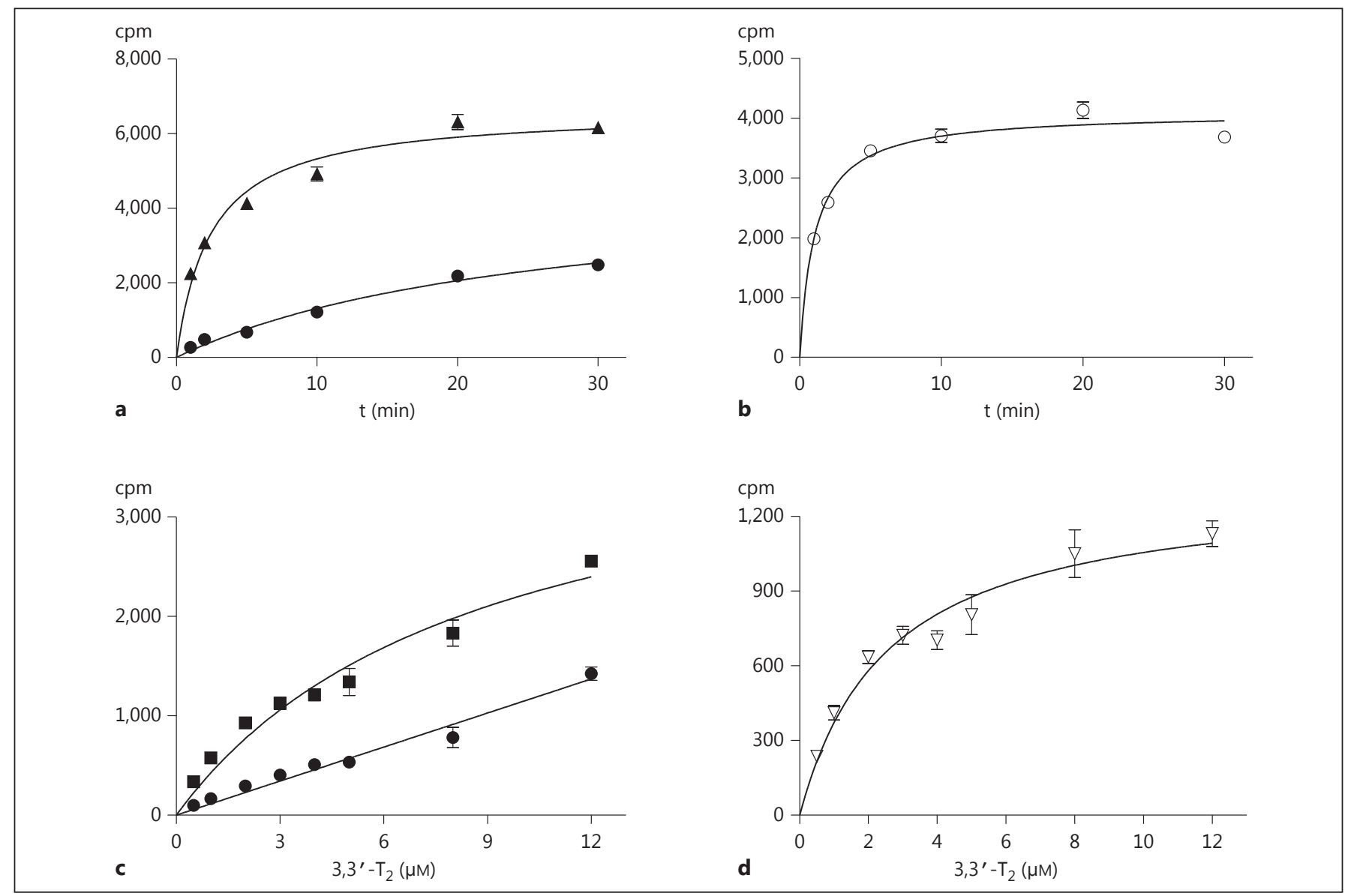

Fig. 5. 3,3'-T ${ }^{\prime}$ uptake in MCT8 $(\mathbf{\Delta})$ or pcDNA3 $(\bullet)$ stably transfected MDCK1 cells. a Time course experiments were measured after incubation of $10 \mathrm{nM} 3,3^{\prime}-\mathrm{T}_{2}$ for $1-30 \mathrm{~min}$ in $\mathrm{Na}^{+}$-free uptake buffer. b Uptake by pcDNA3-transfected cells was considered as background and subtracted $(\mathrm{O})$. c, d The concentration depen-

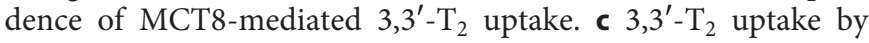
MCT8 was measured at different substrate concentrations (0.5-12 $\mu \mathrm{M})$ in $\mathrm{Na}^{+}$-free uptake buffer without BSA in MCT8- ( $)$and pcDNA3- ( ) transfected MDCK1 cells after 2 min. $\mathbf{d}$ The transport activity of pcDNA3-transfected cells was subtracted from that of MCT8-expressing cells and a Michaelis-Menten transport mechanism was assumed for calculations $(\nabla)$ using GraphPad 4.0. Data correspond to a representative experiment performed in triplicate. $\mathrm{A} \mathrm{K}_{\mathrm{m}}$ value of $2.6 \mu \mathrm{M}$ was determined. e Inhibition on MCT8-mediated 3,3'- $\mathrm{T}_{2}$ uptake by $10 \mu \mathrm{M}$ iodothyronines. Uptake of pcDNA3-transfected cells was considered as background and subtracted. Uptake without an inhibitor was set to 100\% (control).

human CD98 in X. laevis oocytes, but only to a small extent the uptake of $\mathrm{T}_{3}$ and $\mathrm{T}_{4}$ [13]. As previously shown, thyroid hormones $\mathrm{T}_{3}$ and $\mathrm{T}_{4}$ show a better competition for leucine uptake in LAT1 than in LAT2 $[18,19]$. In both studies the uptakes of L-Leu by LAT1 were markedly inhibited by $\mathrm{T}_{3}$ and to a smaller extent by $\mathrm{T}_{4}$. In compari-

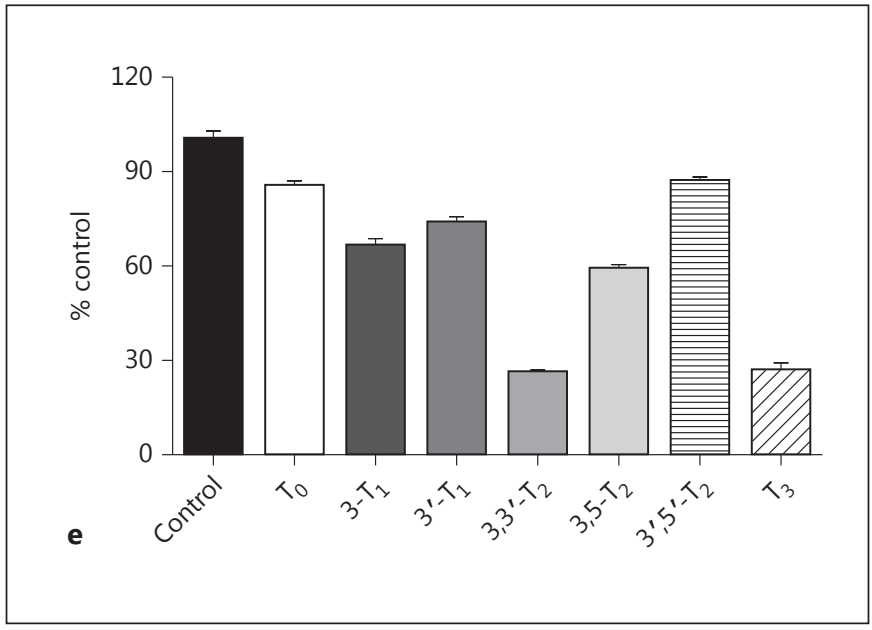

son, $\mathrm{T}_{3}$ and $\mathrm{T}_{4}$ showed a milder effect on L-Leu uptake and no inhibition on L-Ala transport by LAT2, respectively $[18,19]$.

In the present study, the injection of oocytes with Lat2 cRNA alone does not induce the transport of the $3,3^{\prime}-\mathrm{T}_{2}$, indicating that expression of a CD98-like heavy chain by 
native oocytes is negligible. However, if oocytes are coinjected with cRNA for both CD98 and Lat2, uptake of the $3,3^{\prime}-T_{2}$ is markedly stimulated above that seen after injection of CD98 cRNA alone, which is characteristic for the heterodimeric transporter Lat2 $[11,20]$.

Interestingly, the uptake by noninjected oocytes was significantly lower when cells were incubated in choline chloride-containing buffer. This observation is in line with findings from Friesema et al. [13], who reported that uptake of iodothyronines by endogenous transporters in oocytes seems to be at least partially sodium dependent. In addition, this correlates to the already mentioned findings where the presence of a sodium-dependent LAT-like transporter in oocytes was reported [21].

For comparison, the substrate affinity of $3,3^{\prime}-\mathrm{T}_{2}$ was also analyzed in uptake measurements of the MCT8 transporter. Visser et al. [4] showed that MCT8 transports $3,3^{\prime}-T_{2}$ using $X$. laevis oocytes as the expression system. The thyroid hormones $K_{m}$ values were calculated in a low micromolar range, for example LAT1, MCT8 and OATP1C1 $[4,15,22,23]$.

Next we asked whether the known LAT inhibitor BCH [24] influences the $3,3^{\prime}-T_{2}$ uptake by Lat 2 . Coincubation of $3,3^{\prime}-\mathrm{T}_{2}$ with $\mathrm{BCH}$ of noninjected oocytes resulted in no significant decrease in the uptake of hormone, suggesting that there is no endogenous expression of LATs in X. laevis oocytes (data not shown).

In addition, we used the 3,3'- $\mathrm{T}_{2}$ uptake for inhibition studies with known Lat2 substrates like L-Leu, L-Ile, LMet and L-His $[18,20]$. All four amino acids resulted in a high competing inhibition of $3,3^{\prime}-\mathrm{T}_{2}$ uptake (fig. 4), which is comparable with previously observed effects of L-Leu on iodothyronine transport by LAT1 [19].

Finally, we tested thyroid hormones, which differ in their number and position of iodine atoms, for inhibition of $3,3^{\prime}-\mathrm{T}_{2}$ transport. $\mathrm{T}_{0}$ and also $\mathrm{T}_{1}$ and $\mathrm{T}_{2}$ derivatives showed a strong inhibitory effect (fig. 4). In contrast, 3,3'$\mathrm{T}_{2}$ transport by MCT8 was only inhibited by iodothyronines carrying at least one iodine atom per aromatic ring like $3,3^{\prime}-\mathrm{T}_{2}$, and $\mathrm{T}_{3}$ (fig. 5). The competition studies on $3,3^{\prime}-\mathrm{T}_{2}$ uptake by MCT8 are comparable with previous findings [15].

Our results are likely influenced by the fact that this transporter is bidirectional. It may also happen that the efflux will increase over time with the amount of imported $\mathrm{T}_{2} / \mathrm{T}_{3}$.

So far, the focus in thyroid research has mainly been directed towards the classical thyroid hormones $\mathrm{T}_{3}$ and $\mathrm{T}_{4}$. Interestingly, diiodothyronines, which are mostly regarded as a mere degradation product, also trigger cellu- lar responses, e.g. cell metabolism. For example, 3,3'- $\mathrm{T}_{2}$ binding sites were discovered in rat mitochondria, suggesting a role in metabolic regulation of the cell [25]. Also, stimulation of the cytochrome oxygenase was noted, but this data has not yet been independently confirmed. While only a few possible biological effects of $3,3^{\prime}-\mathrm{T}_{2}$ and $3^{\prime}, 5^{\prime}-\mathrm{T}_{2}$ have been reported, there is more information available for $3,5-\mathrm{T}_{2}$, which circulates in human serum [26] and might rapidly and directly act on mitochondrial function and at higher concentrations also mimics $\mathrm{T}_{3}$ effects via modulation of TR-dependent transcription in many target cells [27-31]. Moreover, it was recently demonstrated that $3,5-\mathrm{T}_{2}$ influences the volume of adipocytes by inducing lipolysis and increases the mitochondrial content in brown adipocytes and thermogenesis, thus demonstrating an influence of $3,5-\mathrm{T}_{2}$ on the metabolism [32]. Recent findings in fish even suggest an activating role of $3,5-\mathrm{T}_{2}$ by binding to the thyroid hormone receptor $\beta 1$, thus remodeling the role of $T_{2}$ in the mode of action of thyroid hormones [33].

Taken together, we not only affirmed previous findings pointing towards an involvement of Lat 2 in the uptake of thyroid hormones, but, as the most important finding, we showed that Lat 2 mainly transports $3,3^{\prime}-\mathrm{T}_{2}$, less $\mathrm{T}_{3}$ and no $\mathrm{rT}_{3}$ and $\mathrm{T}_{4}$. One of the questions that remains to be clarified is the extent to which cellular uptake of iodothyronines through Lat 2 is stimulated by countertransport of different intracellular iodothyronines or amino acids. This is because Lat 2 was described as an amino acid exchanger and could also be involved in the efflux of these substrates [34].

\section{Acknowledgments}

This work was supported by grants from the Deutsche Forschungsgemeinschaft DFG, Project SPP Thyroid Trans Act 1629 (Ki1751/1-1, Kr1273/5-1, WI3768/2-1, KO 922/17-1).

We would like to thank Jens Furkert for technical assistance during radioactive transport measurements and Thomas Jentsch for providing us the pTLB plasmid and oocytes from X. laevis.

\section{Disclosure Statement}

The authors have nothing to disclose. 


\section{References}

$>1$ Bernal J, Nunez J: Thyroid hormones and brain development. Eur J Endocrinol 1995; 133:390-398.

$\checkmark 2$ Zoeller TR, Dowling AL, Herzig CT, Iannacone EA, Gauger KJ, Bansal R: Thyroid hormone, brain development, and the environment. Environ Health Perspect 2002;110:355.

$\checkmark 3$ Silva JE: Thyroid hormone control of thermogenesis and energy balance. Thyroid 1995;5: 481-492.

$\checkmark 4$ Visser WE, Friesema EC, Visser TJ: Minireview: thyroid hormone transporters: the knowns and the unknowns. Mol Endocrinol 2011;25:1-14.

5 Kinne A, Schülein R, Krause G: Primary and secondary thyroid hormone transporters. Thyroid Res 2011;4:S7.

$\checkmark 6$ Wirth EK, Roth S, Blechschmidt C, Hölter SM, Becker L, Racz I, Zimmer A, Klopstock T, Gailus-Durner V, Fuchs H: Neuronal 3',3,5-triiodothyronine $\left(\mathrm{T}_{3}\right)$ uptake and behavioral phenotype of mice deficient in Mct8, the neuronal $\mathrm{T}_{3}$ transporter mutated in AllanHerndon-Dudley syndrome. J Neurosci 2009; 29:9439-9449.

7 Braun D, Kinne A, Bräuer AU, Sapin R, Klein MO, Köhrle J, Wirth EK, Schweizer U: Developmental and cell type-specific expression of thyroid hormone transporters in the mouse brain and in primary brain cells. Glia 2011;59: 463-471.

-8 Braun D, Wirth EK, Wohlgemuth F, Reix N, Klein MO, Gruters A, Kohrle J, Schweizer U: Aminoaciduria, but normal thyroid hormone levels and signalling, in mice lacking the amino acid and thyroid hormone transporter Slc7a8. Biochem J 2011;439:249-255.

$\checkmark 9$ Núñez B, de Mena RM, Obregon MJ, FontLlitjós M, Nunes V, Palacín M, Dumitrescu AM, Morte B, Bernal J: Cerebral cortex hyperthyroidism of newborn Mct8-deficient mice transiently suppressed by Lat 2 inactivation. PloS One 2014;9:e96915.

$>10$ Rossier G, Meier C, Bauch C, Summa V, Sordat B, Verrey F, Kühn LC: LAT2, a new basolateral 4F2hc/CD98-associated amino acid transporter of kidney and intestine. J Biol Chem 1999;274:34948-34954.

11 Pineda M, Fernández E, Torrents D, Estévez R, López C, Camps M, Lloberas J, Zorzano A, Palacín M: Identification of a membrane protein, LAT-2, that co-expresses with 4F2 heavy chain, an L-type amino acid transport activity with broad specificity for small and large zwitterionic amino acids. J Biol Chem 1999;274: 19738-19744.
12 Broer A, Friedrich B, Wagner C, Fillon S, Ganapathy V, Lang F, Broer S: Association of 4F2hc with light chains LAT1, LAT2 or $\mathrm{y}^{+}$LAT2 requires different domains. Biochem J 2001;355:725-731.

13 Friesema EC, Docter R, Moerings EP, Verrey F, Krenning EP, Hennemann G, Visser TJ: Thyroid hormone transport by the heterodimeric human system $\mathrm{L}$ amino acid transporter. Endocrinology 2001;142:4339-4348.

14 Schmidt-Rose T, Jentsch TJ: Transmembrane topology of a CLC chloride channel. Proc Natl Acad Sci USA 1997;94:7633-7638.

15 Kinne A, Kleinau G, Hoefig CS, Grüters A, Köhrle J, Krause G, Schweizer U: Essential molecular determinants for thyroid hormone transport and first structural implications for monocarboxylate transporter 8 . J Biol Chem 2010;285:28054-28063.

16 Friesema EC, Ganguly S, Abdalla A, Fox JEM, Halestrap AP, Visser TJ: Identification of monocarboxylate transporter 8 as a specific thyroid hormone transporter. J Biol Chem 2003;278:40128-40135.

17 Brown DD: A tribute to the Xenopus laevis oocyte and egg. J Biol Chem 2004;279:4529145299.

18 Morimoto E, Kanai Y, Kim DK, Chairoungdua A, Choi HW, Wempe MF, Anzai N, Endou $\mathrm{H}$ : Establishment and characterization of mammalian cell lines stably expressing human L-type amino acid transporters. J Pharmacol Sci 2008;108:505-516.

19 Khunweeraphong N, Nagamori S, Wiriyasermkul P, Nishinaka Y, Wongthai P, Ohgaki R, Tanaka H, Tominaga H, Sakurai H, Kanai Y: Establishment of stable cell lines with high expression of heterodimers of human 4F2hc and human amino acid transporter LAT1 or LAT2 and delineation of their differential interaction with $\alpha$-alkyl moieties. J Pharmacol Sci 2012;119:368-380.

20 Segawa H, Fukasawa Y, Miyamoto K, Takeda E, Endou H, Kanai Y: Identification and functional characterization of a $\mathrm{Na}^{+}$-independent neutral amino acid transporter with broad substrate selectivity. J Biol Chem 1999;274: 19745-19751.

21 Broer A, Hamprecht B, Broer S: Discrimination of two amino acid transport activities in 4F2 heavy chain-expressing Xenopus laevis oocytes. Biochem J 1998;333:549-554.

22 Pizzagalli F, Hagenbuch B, Stieger B, Klenk U, Folkers G, Meier P: Identification of a novel human organic anion transporting polypeptide as a high affinity thyroxine transporter. Mol Endocrinol 2002;16:2283-2296.

23 Tohyama K, Kusuhara H, Sugiyama Y: Involvement of multispecific organic anion transporter, Oatp14 (Slc21a14), in the transport of thyroxine across the blood-brain barrier. Endocrinology 2004;145:4384-4391.
24 Christensen HN, Handlogten ME, Lam I, Tager HS, Zand R: A bicyclic amino acid to improve discriminations among transport systems. J Biol Chem 1969;244:1510-1520.

$\checkmark 25$ Lanni A, Moreno M, Horst C, Lombardi A, Fernando G: Specific binding sites for 3,3' -diiodo-L-thyronine $\left(3,3^{\prime}\right.$-T2) in rat liver mitochondria. FEBS Lett 1994;351:237-240.

26 Lehmphul I, Brabant G, Wallaschofski H, Ruchala M, Strasburger CJ, Köhrle J, Wu Z: Detection of 3,5-diiodothyronine in sera of patients with altered thyroid status using a new monoclonal antibody-based chemiluminescence immunoassay. Thyroid 2014;24: 1350-1360.

27 Jonas W, Lietzow J, Wohlgemuth F, Hoefig CS, Wiedmer P, Schweizer U, Köhrle J, Schürmann A: 3,5-Diiodo-L-thyronine (3,5- $\left.\mathrm{T}_{2}\right)$ exerts thyromimetic effects on hypothalamuspituitary-thyroid axis, body composition, and energy metabolism in male dietinduced obese mice. Endocrinology 2014;156:389-399.

28 Pietzner M, Lehmphul I, Friedrich N, Schurmann C, Ittermann T, Dörr M, Nauck M, Laqua R, Völker U, Brabant G: Translating pharmacological findings from hypothyroid rodents to euthyroid humans: is there a functional role of endogenous $3,5-\mathrm{T}_{2}$ ? Thyroid 2015;25:188-197.

29 Padron AS, Neto RAL, Pantaleão TU, de Souza dos Santos MC, Araujo RL, de Andrade BM, da Silva Leandro M, de Castro JPSW, Ferreira ACF, de Carvalho DP: Administration of 3,5-diiodothyronine $\left(3,5-\mathrm{T}_{2}\right)$ causes central hypothyroidism and stimulates thyroid-sensitive tissues. J Endocrinol 2014;221: 415-427.

30 Moreno M, de Lange P, Lombardi A, Silvestri E, Lanni A, Goglia F: Metabolic effects of thyroid hormone derivatives. Thyroid 2008;18: 239-253.

31 Ball S, Sokolov J, Chin W: 3,5-Diiodo-L-thyronine $\left(\mathrm{T}_{2}\right)$ has selective thyromimetic effects in vivo and in vitro. J Mol Endocrinol 1997; 19:137-147.

32 Smit J, Visser T: 37 th annual meeting of The European Thyroid Association: abstracts Leiden, The Netherlands, September 7-11, 2013. Eur Thyroid J 2013; 2(suppl 1):75-194.

33 Mendoza A, Navarrete-Ramírez P, Hernández-Puga G, Villalobos P, Holzer G, Renaud J, Laudet V, Orozco A: 3,5- $T_{2}$ is an alternative ligand for the thyroid hormone receptor $\beta 1$. Endocrinology 2013;154:2948-2958.

34 Meier C, Ristic Z, Klauser S, Verrey F: Activation of system $L$ heterodimeric amino acid exchangers by intracellular substrates. EMBO J 2002;21:580-589. 